\title{
RANCANG BANGUN TEMPAT SAMPAH OTOMATIS PADA UNIVERSITAS LABUHANBATU
}

\author{
Iwan Purnama ${ }^{1)}$, Syaiful Zuhri Harahap ${ }^{2)}$, Ali Akbar Ritonga ${ }^{3)}$ \\ Dosen Fakultas Sains dan Teknologi, Universitas Labuhanbatu \\ iwanpurnama2014@gmail1), syaifulzuhriharahap@gmail.com ${ }^{2)}$, aliakbarritonga@gmail.com ${ }^{3)}$
}

\begin{abstract}
ABSTRAK
Sampah merupakan masalah primer yang berakibat tidak baik terhadap lingkungan. Tidakterkontrolnya kondisi tong sapah penuh serta kurangnya kepedulian setiap orang untuk membuangsampah pada tempatnya bahkan mengolah atau mendaur ulang sampah tersebut menjadi salahsatu penyebabnya. Mahasiswa merupakan generasi penerus yang memiliki peran penting untukselalu menjaga lingkungan agar tidak tercemar oleh sampah, sehingga sangat tepat untukmembiasakan menjaga lingkungan dengan membuang sampah pada tempatnya. Hal inimendorong pelaksana untuk membuat Tong Sampah Pintar yang dapat berperan sebagaipengingat atau pemberi informasi tentang pentingnya menjaga lingkungan kepada mahasiswa di lingkungan Universitas Labuhanbatu. Tong sampah pintar ini dibangun dengan menggunakansensor-sensor Ultrasonicyang bekerja secara otomatis dengan keluaran otomatis membuka dan menutup tutup tong sampah yang diprosespada Arduino. Dengan sistem yang dibangun diharapkan dapat menjadi sarana edukasikepada mahasiswa akan pentingnya menjaga lingkungan yang sehat danmembiasakan untuk membuang sampah pada tempatnya dengan daya tarik sistem pada tong sampah pintar.
\end{abstract}

\section{Kata kunci: Arduino, Tong Sampah, Ultrasonic, Kebersihan}

\begin{abstract}
Garbage is a primary problem that results in no good for the environment. The uncontrolled condition of full sap drums and the lack of concern of everyone to dispose of garbage in its place and even process or recycle it is one of the causes. Students are the next generation who have an important role to always protect the environment so that it is not polluted by rubbish, so it is very appropriate to get used to protecting the environment by disposing of trash in its place. This encourages implementers to create a Smart Trash Can that can act as a reminder or information provider about the importance of protecting the environment for students at Labuhanbatu University. This smart garbage can is built using Ultrasonic sensors that work automatically with automatic output opening and closing the garbage can that is processed in Arduino. With the system built it is expected to be a means of education to students on the importance of maintaining a healthy environment and getting used to dispose of trash in its place with the appeal of the system on smart trash cans.
\end{abstract}

Keywords: Arduino, Trash Can, Ultrasonic, Cleanliness. 


\section{PENDAHULUAN}

Sampah merupakan masalah serius dalam isu lingkungan kehidup. Setiap waktu manusia menghasilkan sampah, baik sampah industry maupun sampah rumah tangga yang bermacam-macam jenis dan bentuk nya. Sampah akan jadi masalah serius karena akan mengganggu kesehatan manusia, menimbulkan bau busuk dan polusi udara[1].

Menurut [2]Jika pengelolaan sampah tersebut tetap tidak ditangani dengan baik akan dapat menyebabkan timbulnya berbagai permasalahan seperti :

1. Gangguan kesehatan

2. Penanganan sampah yang tidak baik dapat menyebabkan timbunan sampah yang dapat menjadi sumber kebakaran.

3. Dapat menutup saluran air sehingga meningkatkan masalah-masalah kesehatan yang berkaitan dengan banjir dan tanah-tanah yang tergenang air.

4. Sebanyak $20 \%$ sampah yang dihasilkan dibuang kekali/sembarangan menyumbang sekitar $60 \%-70 \%$ pencemaran sungai.

Pengolahan sampah yang tidak baik dapat menyebabkan masalah lingkungan yang yang serius merugikan kehidupan manusia. Tempat sampah yang sudah disediakan oleh instansi kebersihan hanya menjadi hiasan bisu di jalanan yang tidak menarik tidak terurus[3].

Sehingga membuat orang merasa malas untuk membuang sampat pada tempatnya. Rasa malas muncul dikarenakan tempat sampah yang ada pada saat ini masih menggunakan cara sederhana yaitu dengan membuka dan menutup tutup tempat sampah secara manual. Hal ini akan menyebabkan tangan akan sangat rawan terkena bakteri dari tempat sampah tersebut[4].

Penelitian yang dilakukan [5]merancang tong sampah otomatis menggunakan arduino yang secara keseluruhan efektif digunakan demi menjaga kesehatan dan kebersihan lingkungan. Penelititan yang dilakukan memberikan solusi dengan membuat smart trash bin berbasis arduino, menggunakan sensor HCSR04 dalam meningkatkan kesadaran akan kepedulian terhadap kebersihan lingkungan.

Mengacu dari penelitian sebelumnya, kaitannya pada penelitian ini adalah bagaimana merancang tempat sampah pintar yang dapat berfungsi untuk menarik minat mahasiswa di Universitas Labuhanbatu agar membuang sampat pada tempatnya dengan berbasis Arduino.

\section{METODE PENELITIAN}

Metode yang digunakan dalam penelitian ini yaitu menggunakan model waterfall[6], dengan tahapan sebagai berikut:

1. Analisis Permasalahan yang terjadi yaitu belum adanya alat untuk mendeteksi penuhnya tempat sampah dan terbuka tutup tempat sampah, peneliti mencoba menggunakan alat yaitu mikrikontroler Arduino sebagai otak dari sistem dan menggunakan software Arduino IDE untuk membuat coding programnya. 
2. Desain Dilakukan perancangan sketsa gambar dan prototype sistem sebagai acuan ukuran alat tempat sampah pintar, kemudian di lanjutkan dengan merancang alat tempat sampah pintar, serta perancangan elektrikalnya.

3. Coding Melakukan pengkodean yang dilakukan pada software Arduino IDE yang akan digunakan dengan bahasa pemrograman $\mathrm{C}$, setelah itu coding dimasukan ke dalam arduino.

4. Pengujian. Melakukan pengujian terhadap skrip/coding yang telah dimasukan, yaitu dengan menguji satu persatu sebelum melakukan untuk pengujian secara keseluruhan.

5. Perawatan. Melakukan perawatan alat tempat sampah pintar dengan menaruh pada tempat yang baik, sehingga terhindar dari hal-hal yang tidak diinginkan. Sedangkan metode pengumpulan data yang dilakukan pada penelitian ini adalah :

a) Observasi, pengumpulan data secara langsung di Universitas Labuhanbatu melalui pengamatan, dicatat dan direduksi kemudian disajikan secara sistematis untuk menggambarkan objek yang diteliti.

b) Wawancara pribadi merupakan instrument yang paling baik untuk memperoleh informasi. Dalam penelitian ini pengumpulan data dengan malalui tanya jawab secara lisan dengan sumber yang bersangkutan secara langsung dan tanpa dengan daftar pertanyaan mengenai tempat sampah yang merupakan alat penampung sampah. c) Studi pustaka, di samping observasi dan wawancara mengumpulan referensi data yang berkaitan dengan perancangan tempat sampah pintar melalui buku-buku, dan jurnal-jurnal yang terkait.

\section{HASIL DAN PEMBAHASAN}

A. Perancangan Sistem

a. Gambaran Umum Perancangan Sistem Perancangan sistem tempat sampah pintar dengan mikrokontrolerarduino dan sensor ultrasonik (HC-SRF04) ini terdiri dari dua perancangan, yaitu perancangan perangkat keras (hardware) meliputi perancangan alat dan perancangan perangkat lunak (software) meliputi source code arduino.

b. Diagram Blok Secara garis besar, perancangan tempat sampah pintar berbasis arduino uno terdiri dari, servo, buzzer, arduino dan sensor ultrasonik HCSRF04 untuk mendeteksi jarak dan volume sampah.

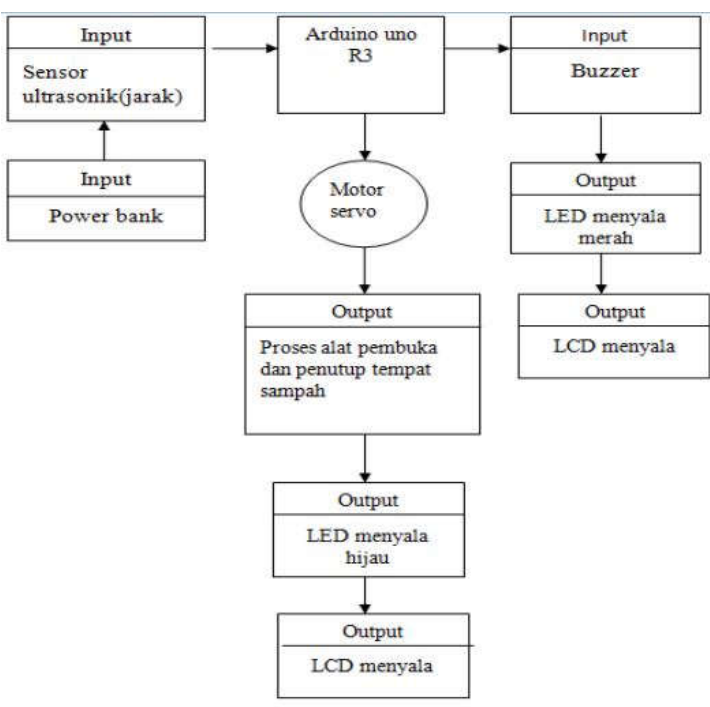

Gambar 1. Diagram Blok Rangkaian 
Keterangan dari blok diagram :

a) Powerbank sebagai menghidupkan dan mematikan tempat sampah pintar.

b) Arduino penghantar program dari tempat sampah pintar.

c) Sensor UltrasonicHC-SRF04 untuk pendeteksi pergerakan tangan pada saat membuang sampah.

d) Motor servo sebagai pembuka dari tutup tempat sampah.

e) Buzzer sebagai sirine pemberitahuan bahwa sampah penuh.

f) LCD sebagai pemberitahuan tempat sampah penuh saat LED menyala merah dan tempat sampah kosong saat LED menyala hijau.

g) LED sebagai pemberitahuan jika

- Berwarna hijau tandanya masih kosong.

- Berwarna merah tandanya penuh.

c. Perancangan Mekanikal Perancangan mekanikal meliputi pembuatan kerangka alat:

Perancangan mekanikal meliputi pembuatan kerangka alat :

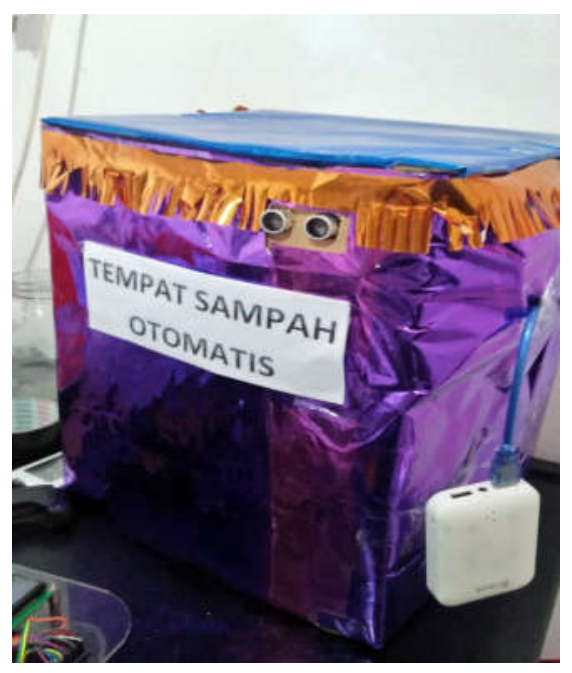

Gambar 2. Hasil Simulasi Tong Sampah Pintar

\section{Flowchart}

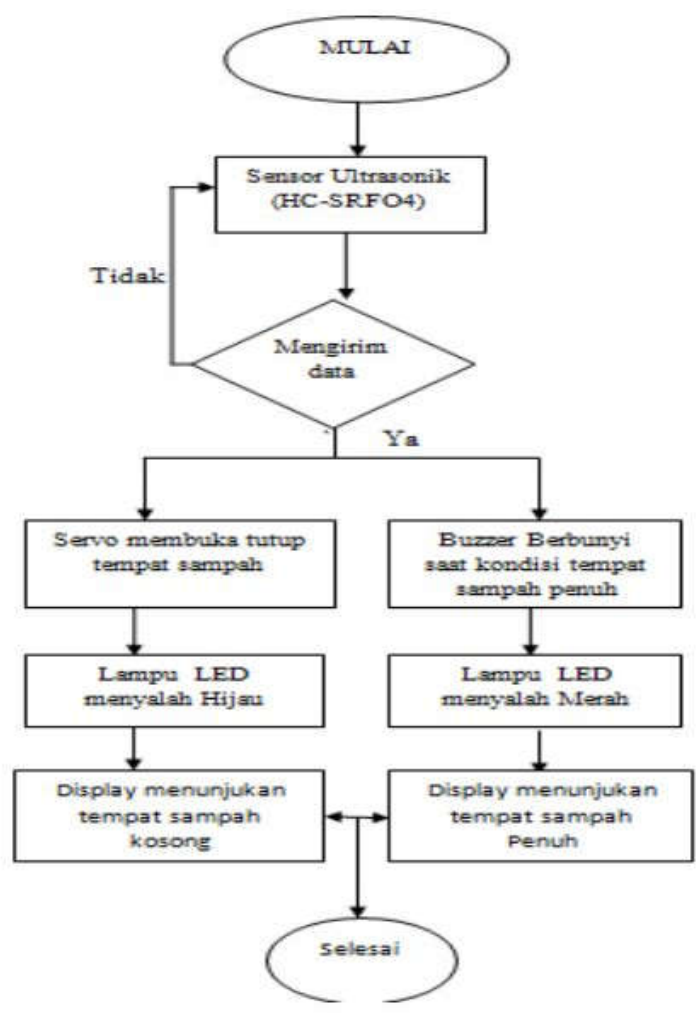

Gambar 3. FlowchartTong Sampah Pintar

\section{KESIMPULAN DAN SARAN}

Setelah dilakukan proses pengujian beberapa kali dan pengambilan data selama beberapa kali, maka tempat sampah pintar berbasis arduino disimpulkan, tempat sampah pintar dengan sensor HC-SRF04 berbasis arduino telah mampu bekerja menjalankan fungsinya dengan baik dan benar, tempat sampah pintar dengan sensor $H C$-SRF04 berbasis arduino ini dapat mendeteksi pergerakan dengan jarak $10 \mathrm{~cm}$ setelah itu secara otomatis servo akan membuka dan menutup tutup tempat sampah dengan sendiri atau otomatis. 


\section{DAFTAR PUSTAKA}

[1] A. Kahfi, "Tinjauan Terhadap Pengelolaan Sampah," Jurisprud. Jur. Ilmu Huk. Fak. Syariah dan Huk., vol. 4, no. 1, p. 12, 2017, doi: 10.24252/jurisprudentie.v4i1.3661.

[2] R. D. Harahap, "Pengaruh Sampah Rumah Tangga Terhadap Pelestarian Lingkungan Ditinjau Dari Aspek Biologi Di Komplek Perumahan Graha Pertiwi Kel. Urung Kompas Kec. Rantau Selatan Effect of Household Waste Viewed From the Aspect Environmental Conservation Biology in Housin," Cahaya Pendidik., vol. 2, no. 1, pp. 92-104, 2016, doi: 10.33373/chypend.v2i1.609.

[3] H. D. Ariessanti, M. Martono, and J. Widiarto, "Sistem Pembuangan Sampah Otomatis Berbasis IOT Menggunakan Mikrokontroler pada SMAN 14 Kab.Tangerang," CCIT $J$, vol. 12, no. 2, pp. 229-240, 2019, doi: 10.33050/ccit.v12i2.694.

[4] D. Almanda, H. Isyanto, and R. Samsinar, "Perancangan Prototype Pemilah Sampah Organik Dan Anorganik Menggunakan Solar Panel 100 Wp Sebagai Sumber Energi Listrik Terbarukan," Semin. Nas. Sains Dan Teknol., pp. 1-9, 2018, [Online]. Available: https:http://jurnal.umj.ac.id/index.p hp/semnastek.

[5] Sukarjadi, D. T. Setiawan, Arifiyanto, and M. Hatta, "Perancangan Dan Pembuatan Smart Trash Bin Berbasis Arduino Uno Di Universitas Maarif Hasyim Latif," Tek. Eng. Sains J., vol. 1, no. 2, pp. 101-110, 2017.
[6] R. U. Tambunan, S. Suryadi, and I. Purnama, "Perancangan Aplikasi Data Buku Perpustakaan Pada Smk Swasta Al - Azis Berbasis Anroid," J. Inform., vol. 5, no. 2, pp. 46-52, 2019, doi: 10.36987/informatika.v5i2.729. 